\title{
COMPARATIVE ANALYSIS OF THE EFFICIENCY OF THERMAL SYSTEMS BUILT WITH REFLECTIVE INSULATORS WITH AND WITHOUT VACUUM
}

\begin{abstract}
M. A.V. Cavalcanti ${ }^{\mathrm{a}}$, ABSTRACT
J. U. L. Mendes ${ }^{a}$, B. T.V. Cavalcanti ${ }^{a}$, and F. F. Silveira ${ }^{\mathrm{a}}$

${ }^{a}$ Universidade Federal do Rio Grande do Norte

Departamento de Engenharia Mecânica

Centro de Tecnologia

Bairro Lagoa Nova

CP. 1524, Natal, RN, Brasil

Alexandre.mecanica@gmail.com

The use of reflective surfaces functioning as thermal insulators has grown significantly over the years. Reflective thermal insulators are materials that have several characteristics such as low emissivity, low absorptivity and high reflectivity in the infrared spectrum. The use of these materials has grown very much lately, since they contain several important radioactive properties that minimize the heat loss of thermal systems and cooling systems that are used to block the heat on the roof of buildings. A system made of three surfaces of 430 stainless steel mirror was built to analyze the influence of reflective surfaces as a way to reduce the heat loss and thereby conserve the energy of a thermal system. The system was analyzed both with and without the presence of vacuum, and then compared with a system that contained glass wool between the stainless steel mirror walls, since this insulator is considered resistive and also broadly used around the world in thermal systems. The reflectivity and emissivity of the surfaces used were also measured in this experiment. A type $\mathrm{K}$ thermocouple was fixed on the wall of the system to obtain the temperature of the stainless steel mirror surfaces and to analyze the thermal behavior of each configuration used. The results showed an efficiency of $13 \%$ when the reflective surfaces were used to minimize the heat loss of the thermal system. However, the system with vacuum had the best outcome, a $60 \%$ efficiency. Both of these were compared to the system made of glass wool as a thermal insulator.
\end{abstract}

Keywords: Reflective surfaces, Thermal insulator, 430 Stainless steel, Heat loss.

\section{NOMENCLATURE}

$\mathrm{I}_{\text {reflected }}$ reflected light intensity, Eq. (1)

$\mathrm{I}_{\text {incident }}$ incident light intensity, Eq. (1)

\section{Greek symbols}

$\rho \quad$ surface reflectivity, (Eq. (1)

\section{INTRODUCTION}

Traditionally, insulating a system has been associated with the use of materials known as conventional resistive or insulating materials, which reduce heat loss by conduction. The use of reflective surfaces in order to minimize the loss of heat in thermal systems is a new concept of energy conservation that's been used worldwide, but still very little explored in Brazil.

The materials used as reflective surfaces are considered thermal insulators by reflection or radiant barriers, since they are able to improve the thermal efficiency of a system, as they reflect the radiant heat instead of absorbing it. These reflective surfaces are made of materials with unique characteristics, such as high capacity of reflection (high reflectivity) and low capacity of transmitting thermal radiation (low emissivity), which are typical characteristics of polished metals (Dare, 2005).

According to (Vittorino, 2003), radiant barriers are found among several reflective insulators available in the domestic market, which began to be used in Brazil in 1995, imported from other countries. Even though the use of these products has grown considerably in recent years, there still doesn't exist a national rule or normalization that addresses this issue specifically. This lack of technical rules has increased the amount of products in the market that do not have satisfactory characteristics to function as thermal isolators, which therefore brings substantial financial loss to those who use this type of product.

\section{THEORY}

The use of reflective insulators is a method of conserving energy recognized for more than 50 years. It is installed in homes, industrial and commercial warehouses, airport hangars, among others. Radiant barriers reduce heat transfer through low emission and high reflection of the incident radiation (Doe, 1991).

This way of reducing the heat dissipation can be done by using materials that have low emissivity such as metal, which is able to emit little heat out of the system by reflecting most of the incident radiation 
into the container. Emissivity is the ability of an object to radiate infrared. On the other hand, reflectivity is a property that determines the fraction of incident energy on the surface of a body that is reflected by that same specific body.

According to (Incropera, 2008), the emissivity of a certain material is due to its surface characteristics. In most materials, the radiation that is emitted by molecules located in the interior of the body is absorbed by other molecules that are located in the adjacent areas, and the only energy that actually leaves the body is the energy emitted by molecules that are located at $1 \mu \mathrm{m}$ of the body surface.

The materials that perform these properties are called reflective thermal insulators or radiant barriers, since they avoid the passage of heat through radiation. Some authors distinguish radiant barriers from reflective insulators; other authors consider these two materials as being pretty much the same thing.

According to (Michels, 2007), radiant barriers are thin and metallic surfaces, usually covered with aluminum, characterized by having at least one surface of low emissivity (approximately 0.05). They are used to reduce the gain of heat by radiation between the tiles and the ceiling (or slab) of residential, commercial and industrial buildings, since they help to save electricity, especially in air conditioned environments. Also in order to avoid heat loss in heating systems, keeping the heat generated inside and thereby reducing the need to increase the thermal power of the heat generating source.

Radiant barriers consist of low emissivity materials, positioned in a building element so that it faces an "environment" that might be the attic space, with or without ventilation, or habitable enclosures, according to (Vittorino, 2003).

On the other hand, reflective insulators are made of multiple and parallel, high reflective layers of thin sheets or blades which are equally spaced between them in order to reflect the radiant energy back to its origin. The spacing between these sheets is designed to restrain the movement of air, and in high performing insulators, there may be vacuum in that space. In all types of insulators, the vacuum in the empty spaces reduces the thermal conductivity of the system (Incropera, 2008).

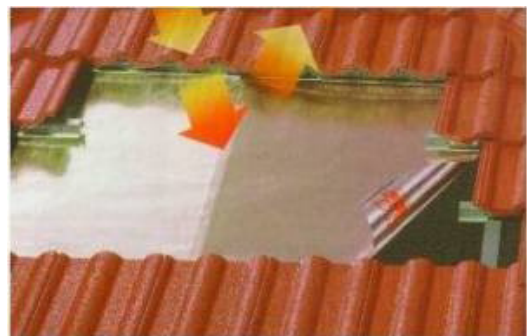

Figure 1. Aluminum barrier of thermal radiation. Source: Armelin (2004).

\section{Applications of radiant barriers}

The main advantages of reflective insulators are their specific and desirable radioactive properties. There are countless applications for this type of insulators, some of which are listed below.

- $\quad$ Facades of residential and commercial buildings - reflective glasses are used to allow the sunlight reflection. Each type of glass has a specific behavior when it comes to solar radiation and the thermal effect of the surfaces depends on the spectral properties of the glasses. According to Holland (2007) reflective glasses are characterized by the deposition of a metallic layer in one of their surfaces. - $\quad$ Electric ovens - Mirrored stainless steel surfaces are used in ovens for heat treatment, aiming to minimize the flow of heat from its inside to the outside and thereby reducing the power consumption.

- Residential under coverage - To avoid the heat transfer from the outside of the environment to its inside due to the temperature gradient in which it is located, a radiant barrier is inserted between the slab and the roof in order to block the radiation, which enables to keep the indoor temperature mild.

\section{METHODS AND EXPERIMENTS}

The system was built using three thin sheets of stainless steel 430, polished on both sides, with dimensions $(30 \times 30) \mathrm{cm}$ and $1 \mathrm{~mm}$ thickness (supplied by Brasinox - Stainless Brazil S/A) with $2.5 \mathrm{~cm}$ spacing between them. The bases that bore the plates were made of wood.

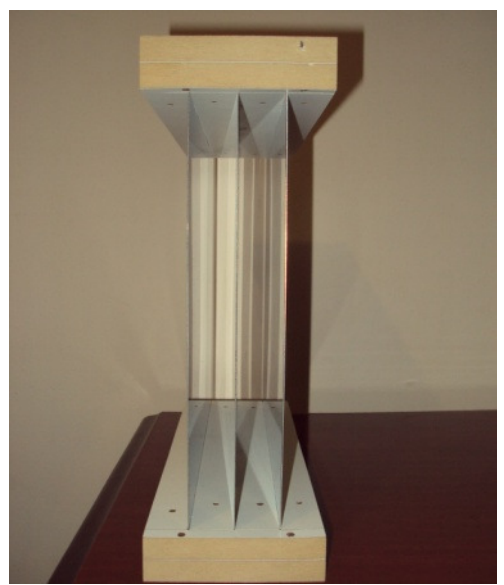

Figure 2. Reflective stainless steel 430 sheets mounted on wooden bases.

A type $\mathrm{K}$ thermocouple was then inserted into each side of the plate surface to monitor the temperatures. A total number of $6 \mathrm{~K}$ thermocouple was used. Each sensor was fixed on the specific surface using durepoxi, because this type of glue is easily applied, has quick drying and withstands high temperatures. After all the thermocouples were fixed, the surface was cleaned using a metal polish to remove stains 
and dust deposited over the setting process, since these variables decreases the surface reflectivity.

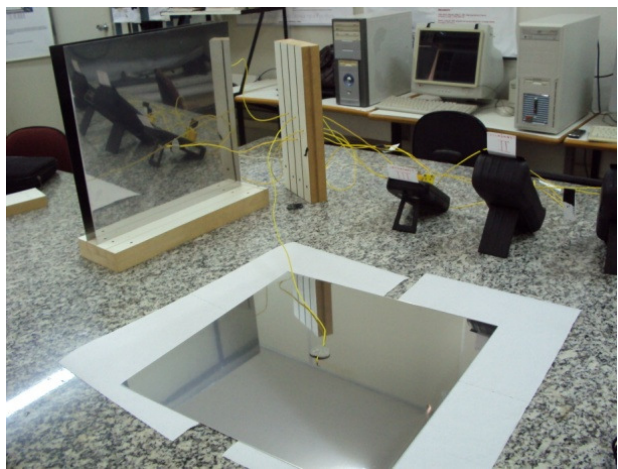

Figure 3. Fixation of thermocouples in stainless steel 430 plates.

A panel made of 4 lamps of $200 \mathrm{~W}$ was used as a heat source for both configurations, accounting a total of $800 \mathrm{~W}$ of radiant power. However, due to the small area of heat transfer and due to the fact that surface reflects part of the incident radiation, the effective radiant energy that actually enters the plate is $35 \mathrm{~W}$ only.

In the first setup, a system of three mirrored surfaces without the presence of vacuum was used. Three digital thermometers were used to measure the temperature, both with range $\left(-50^{\circ} \mathrm{C} 750^{\circ} \mathrm{C}\right)$ and 2 entries. One of the thermometers was a model MT914 and the other two were Model MT-306. The thermocouples "1 and 2" (K type) were inserted on thermometer I, thermocouples "3 and 4" (K type) were placed on thermometer II, and finally, the thermocouple "5 and 6" were inserted on thermometer III, as shown on Figure 4.
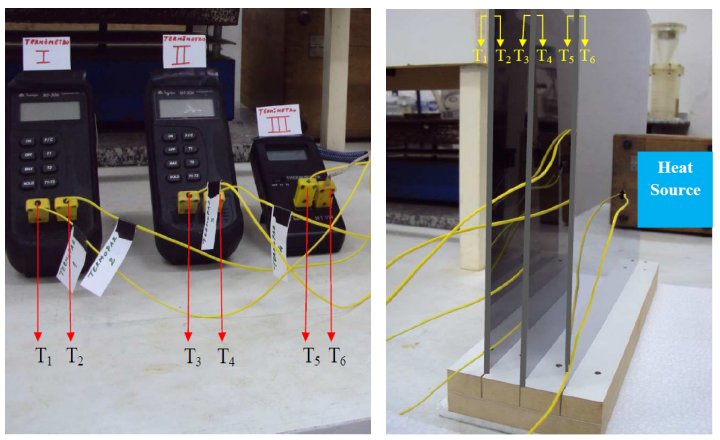

Figure 4. Sequential fixation of the thermocouples on the surfaces of steel plates.

The temperatures were recorded and written down every 5 minutes until the moment that the system entered in steady state. The local temperature of the environment recorded was $25^{\circ} \mathrm{C}$.

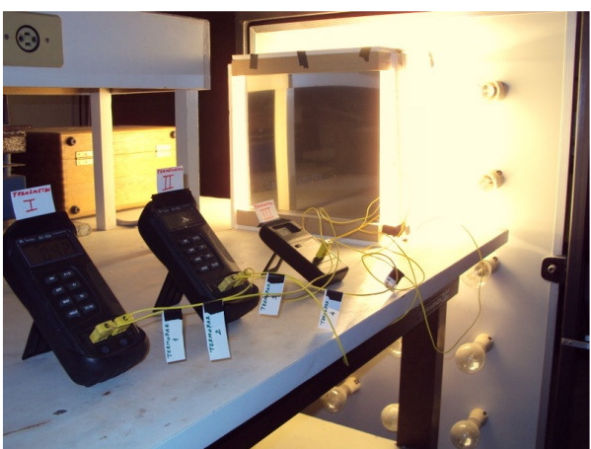

Figure 5. Temperature measurement test without the presence of vacuum.

On the second configuration, a system made of three mirrored surfaces with the presence of vacuum was built this time. A vacuum diaphragm pump model LSDVP-050 by LOGEN SCIENTIFIC was inserted during the test, with a $\left(7^{\circ} \mathrm{C} \sim 40^{\circ} \mathrm{C}\right)$ work temperature and final vacuum until $0.08 \mathrm{PM}$.

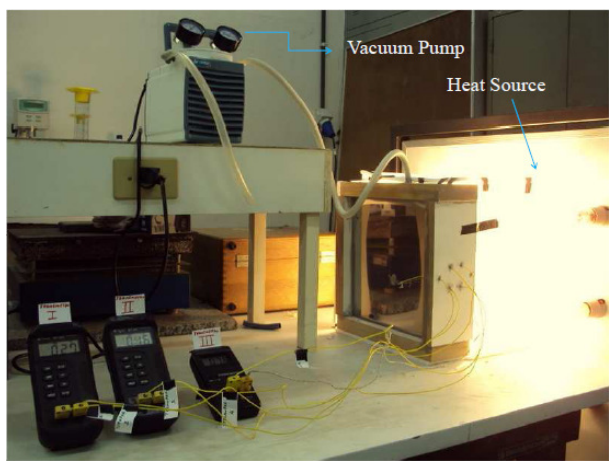

Figure 6. Temperature measurement test with the presence of vacuum.

Aiming to create vacuum in the thermal system, a hole was made on its upper part to enable the insertion of the hose of the vacuum pump and thereby remove the air contained in the recipient.

It was necessary to leave it airtight to decrease the maximum air intake possible. In order to improve the seal of the system, silicone and sealant used in high temperature engines was inserted on the surfaces of the wooden bases, on the thermocouple plug wires and on the insertion of the pump hose.

The maximum pressure reached in the experiment after optimization of the system was of 0.06 PM. It is important to notice that the vacuum was obtained through a dynamic test.

The temperature measurement started after the pump removed the maximum amount of air out of the recipient, stabilizing the pressure of suction. Thereafter, the source of heat was turned on and the temperature values of the surfaces obtained were written down until the temperature stabilized and the system entered a steady state.

On the third configuration, the central plate where thermocouples " 3 and 4" (that belong to 
thermometer II) were located was removed from the system and then all the empty space was filled with two blankets of glass wool, each with one a thickness of $2.5 \mathrm{~cm}$. The blankets were placed to fill the whole space of the container, as shown in Figure 7.

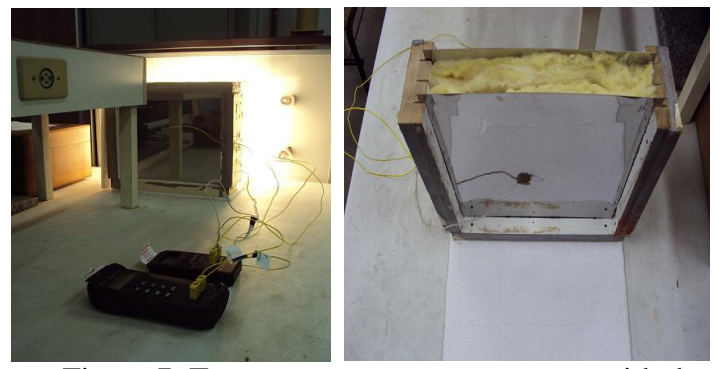

Figure 7. Temperature measurement test with the presence of glass wool.

The measurements of the incident and reflected radiation intensity to determine the reflectivity of the material was done by using a light meter (range of 0300LX e 0-300KLX, producer PHYWE), which is an equipment that measures the intensity of light. The intensity of the incident and reflected radiation was measured to obtain the reflectivity of the steel inox 430.

A lantern of 5 LED was used as a source of thermal radiation to accomplish the measurements of the reflectivity. It was located forming angles of $15^{\circ}$, $30^{\circ}, 45^{\circ}$ and $60^{\circ}$.

The same procedure used to obtain the intensity of the reflected radiation was used to determine the intensity of the incident light. However, since the radiation of the incident light that reaches the surface corresponds to the total value, the measurement was achieved by using the radiation source and the meter located at a $6 \mathrm{~cm}$ frontal distance from the plate, because all the radiation that reaches the sensor is registered by the instrument, as shown in Figure 8.

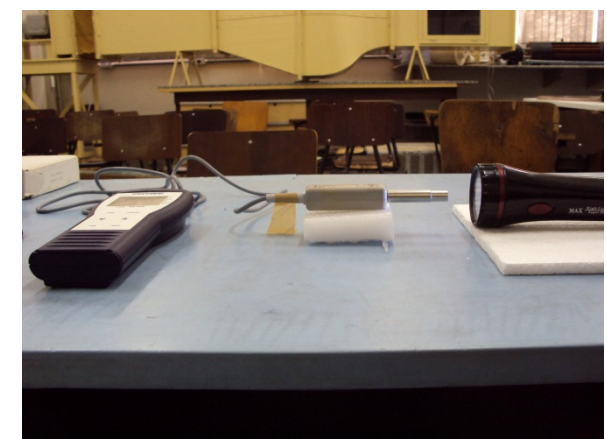

Figure 8 . Measurement of reflectivity by a light meter.

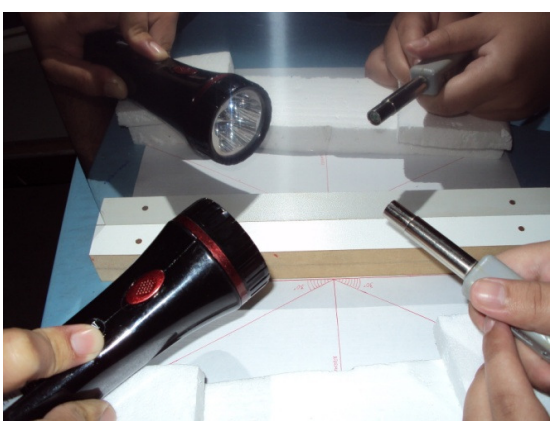

Figure 9. Measurement of reflectivity by a light meter.

The determination of the reflectivity was calculated using Equation 1.

$$
\rho=\frac{I_{\text {reflected }}}{I_{\text {incident }}}
$$

$\rho$ represents the reflectivity (dimensionless), $\mathrm{I}_{\text {reflected }}$ is the reflected light intensity in Lux (lx), $\mathrm{I}_{\text {incident }}$ is the incident intensity in Lux (lx).

The emissivity of the material was calculated by using a digital thermometer without contact with the laser point and with contact with a type $\mathrm{K}$ thermocouple, model PM -1050, manufacturer POLIMED, adjustable emissivity: 0.1 to 1 , noncontact range $\left(-20^{\circ} \mathrm{C}\right.$ to $\left.600^{\circ} \mathrm{C}\right)$ resolution of $1^{\circ} \mathrm{C}$ and contact range $\left(-50^{\circ} \mathrm{C}\right.$ to $\left.1333^{\circ} \mathrm{C}\right)$ with a resolution of $0.1^{\circ} \mathrm{C}$ range for $-50{ }^{\circ} \mathrm{C}$ to $199^{\circ} \mathrm{C}$ and resolution of $1^{\circ} \mathrm{C}$ range for $200^{\circ} \mathrm{C}$ to $1333^{\circ} \mathrm{C}$.

Figure 10 shows the temperature measurement of the surface using a type $\mathrm{K}$ contact digital thermometer. The temperature found will be used as a reference value to find the emissivity of the material in an indirect way.

Finally, the emissivity at room temperature was found by using the digital thermometer with laser point and without contact at a distance of $10 \mathrm{~cm}$, where the emissivity was adjusted until the temperature reached the one given by the contact thermometer.

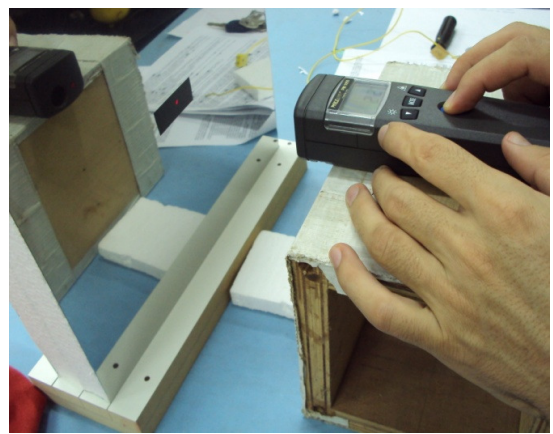

Figure 10. Measurement of contact temperature and measurement of emissivity of stainless steel 430 . 


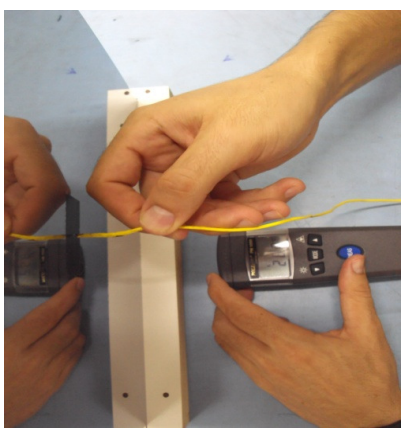

Figure 11. Measurement of contact temperature and measurement of emissivity of stainless steel 430 .

\section{RESULTS AND DISCUSSION}

The value of emissivity of the stainless steel 430 found through the optical pyrometer was of 0.18 . The value of reflectivity found was of 40.6, for an incidence angle of $15^{\circ}$.

Table 1 shows the measured values of reflectivity of the surface of the stainless steel 430 plate according to the angle of incidence.

Table 1. Measured values of reflectivity of the surface of the stainless steel 430 plate.

\begin{tabular}{ccc}
\hline $\begin{array}{c}\text { Angle of } \\
\text { incidence }\left({ }^{\circ}\right)\end{array}$ & $\begin{array}{c}\text { Reflected intensity } \\
(\text { LX) }\end{array}$ & $\begin{array}{c}\text { Values of } \\
\text { reflectivity (\%) }\end{array}$ \\
\hline 15 & 52 & 40,6 \\
\hline 30 & 50 & 39,06 \\
\hline 45 & 49 & 38,3 \\
\hline 60 & 46 & 35,93 \\
\hline & Average & 38,47 \\
\hline
\end{tabular}

Table 2 shows the time that each type of insulator comes into permanent regime. That's the time where all temperatures have stabilized, becoming the heat flux constant.

Table 2. Settling time of the temperatures of each mode of isolation.

\begin{tabular}{|c|c|}
\hline Isolation Mode & $\begin{array}{c}\text { Stabilization time of temperatures } \\
\text { (minutes) }\end{array}$ \\
\hline Glass wool & 55 \\
\hline $\begin{array}{c}\text { Radiant barrier with } \\
\text { vacuum }\end{array}$ & 75 \\
\hline $\begin{array}{c}\text { Radiant barrier with } \\
\text { air }\end{array}$ & 85 \\
\hline
\end{tabular}

The system that showed the least time to reach steady state was the one with the glass wool insulator, followed by the one constructed with radiant barrier with the presence of vacuum and at last, the system constructed with radiant barrier with air.

Table 3 shows a comparison of the temperature differential between the surfaces 1 and 6 for each isolation mode in steady state.
Table 3. Comparison of maximum temperature difference in each system isolation mode.

\begin{tabular}{|c|c|c|c|}
\hline Isolation Mode & $\begin{array}{c}\mathrm{T}_{1} \\
\left({ }^{\circ} \mathrm{C}\right)\end{array}$ & $\begin{array}{c}\mathrm{T}_{6} \\
\left({ }^{\circ} \mathrm{C}\right)\end{array}$ & $\begin{array}{c}\text { differential of Total } \\
\text { Temperature }\left({ }^{\circ} \mathrm{C}\right)\end{array}$ \\
\hline $\begin{array}{c}\text { Glass wool insulation } \\
\text { barrier }\end{array}$ & 45 & 161 & 116 \\
\hline $\begin{array}{c}\text { Insulation with a radiant } \\
\text { barrier with presence of } \\
\text { vacuum }\end{array}$ & 44 & 146 & 102 \\
\hline $\begin{array}{c}\text { Insulation with a radiant } \\
\text { barrence }\end{array}$ & 39 & 120 & 81 \\
\hline
\end{tabular}

Table 4 shows the energy loss of each isolation configuration.

Table 4. Comparison of heat flux of the three modes of isolation system.

\begin{tabular}{|c|c|c|c|c|}
\hline $\begin{array}{c}\text { Isolation } \\
\text { Mode }\end{array}$ & $\begin{array}{c}\text { Conductive } \\
\text { loss (W) }\end{array}$ & $\begin{array}{c}\text { Convectiv } \\
\text { e Loss } \\
\text { (W) }\end{array}$ & $\begin{array}{c}\text { Radiative } \\
\text { loss (W) }\end{array}$ & $\begin{array}{c}\text { Total } \\
\text { Loss } \\
\text { (W) }\end{array}$ \\
\hline $\begin{array}{c}\text { Glass wool } \\
\text { insulation }\end{array}$ & 6,31 & - & - & 6,31 \\
\hline $\begin{array}{c}\text { Insulation } \\
\text { with a radiant } \\
\text { barrier }\end{array}$ & - & 3,88 & 1,65 & 5,53 \\
\hline $\begin{array}{c}\text { Insulation } \\
\text { with a radiant } \\
\text { barrier with } \\
\text { presence of } \\
\text { vacuum }\end{array}$ & - & - & 2,52 & 2,52 \\
\hline
\end{tabular}

Table 5 shows a comparison of the efficiency of the three modes of isolation.

Table 5. Comparative efficiency of methods of thermal insulation.

\begin{tabular}{|c|c|c|}
\hline Isolation Mode & $\begin{array}{c}\text { Efficiency of methods } \\
\text { for isolation by } \\
\text { reflection with respect } \\
\text { to the mode of } \\
\text { insulation with glass } \\
\text { wool. }\end{array}$ & $\begin{array}{c}\text { Efficiency of } \\
\text { isolation methods for } \\
\text { non-vacuum } \\
\text { reflection with } \\
\text { respect to isolation } \\
\text { mode by reflection } \\
\text { with vacuum. }\end{array}$ \\
\hline $\begin{array}{c}\text { Insulation with } \\
\text { a radiant } \\
\text { barrier with } \\
\text { air. }\end{array}$ & $12 \%$ & - \\
\hline $\begin{array}{c}\text { Insulation with } \\
\text { a radiant } \\
\text { barrier in the } \\
\text { presence of } \\
\text { vacuum }\end{array}$ & $60 \%$ & \\
\hline \multicolumn{2}{|c|}{} & \\
\hline
\end{tabular}




\section{CONCLUSIONS}

The use of reflective surfaces that function as reflective insulators is a more efficient way to conserve energy than the use of conventional resistive insulators.

The system constructed with radiant barriers with the presence of vacuum showed a better result than expected, since its energy loss was the lowest.

The decrease in time for the establishment of a steady state in the system with the presence of vacuum is associated with the absence of convective energy.

From an operational and assembly standpoint, the reflective thermal insulators can still be considered as the best way to block heat flow.

\section{ACKNOWLEDGEMENTS}

Thanks to PPGEM/UFRN, to the Laboratory of Mechanical Fluids for all the learning and for the space allotted, thanks to BRASINOX for donating the plates of stainless steel, and Capes for funding scholarships for the lab.

\section{REFERENCES}

Armelin, H. S., and Cherry, N., 2004, Evaluation of the use and performance of thermal radiation barriers in construction. E-magazine Mat, Vol. 1, No. 1, pp. 79-82.

Dare, C. A. N., Targa, L. A, and Isa, M. M., 2005, Evaluating the effectiveness of thermal insulation by reflection, used as under-coverage. Energ. Agric., Botucatu, Vol. 20, No. 2, pp. 14-29.

Vittorino, F., Sato, N. M. N., and Akutsu, M., 2003, Thermal performance of radiant barriers and reflective insulation used in roofing. In: National Meeting of Comfort in the Built Environment, Curitiba, Paraná. ENCAC, pp. 1277-1284.

Department of Energy/CE-0335P., 1991, Assistant Secretary. Energy Efficiency and Renewable Energy. Radiant barrier attic fact sheet. < http://www.ornl.gov/sci/roofs+walls/radiant/rb_01.ht $\mathrm{ml}>$.

Incropera, F. P., DeWitt, D. P., Bergman, and TL., Lavine, A. S., 2008, Fundamentals of heat and mass transfer, $6^{\text {th }}$ ed. Rio de Janeiro: LTC.

Holland, A., Tiger, D., Moura, E., Adeildo, G., and Batista, J., 2007, Reflective glass and the effect on the thermal load of buildings. Recife.

Received: June 09, 2009

Revised: July 09, 2009

Accepted: August 09, 2009 